\title{
La guerra de objetos contra los moche
}

Jürgen Golte'

Resumen

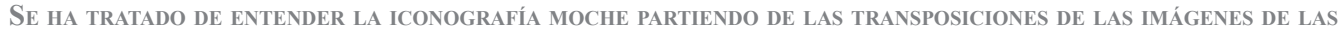
VASIJAS A CUADROS BIDIMENSIONALES. No OBSTANTE ESTA CONVENCIÓN EUROCENTRISTA IMPIDIÓ EN BUENA CUENTA QUE SE AVANZARA EN LA COMPRENSIÓN DE LA LÓGICA DE LAS MISMAS, YA QUE LA PINTURA TRIDIMENSIONAL LOGRA UNA MAYOR TRANSMISIÓN DE SIGNIFICAdOS. EN EL PRESENTE ARTíCULO SE ANALIZAN LOS DISTINTOS SIGNIFICADOS QUE SURGEN A PARTIR DE LA COMPRENSIÓN TRIDIMENSIONAL DEL MITO MOCHICA PLASMADO EN LAS VASIJAS: "LA GUERRA

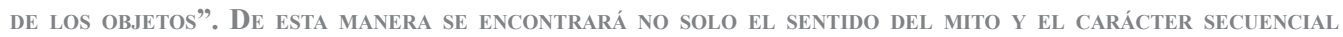
EN QUE ESTÁ REPRESENTADO, SINO LA FORMA EN LA QUE SE LO NARRA -ESCENAS ESENCIALES Y SECUNDARIAS-; LAS RELACIONES ENTRE LOS ACTORES DE LA COSMOLOGÍA MOCHE; Y LAS SUBDIVISIONES DE ESTE UNIVERSO BIPARTITO -MUNDO DE ARRIBA/MUNDO DE ABAJO: MASCULINO/FEMENINO- APLICADAS A LA ORGANIZACIÓN DEL TIEMPO Y CASI CUALQUIER OTRO FENÓMENo dEL MUNDO EXISTENTE. FinALMENTE SE TRATA EN FORMA BREVE LAS ESCENAS DE GUERRA EN LAS PINTURAS MOCHICA.

Palabras Clave: Moche - iconografía - Significado - Mito.

\section{Abstract}

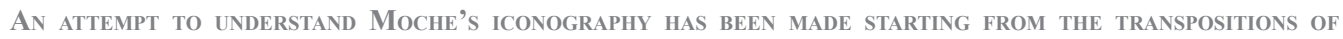

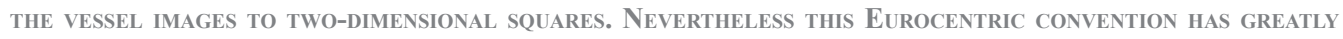
LIMITED ADVANCEMENTS IN COMPREHENDING THE LOGIC OF THIS ICONOGRAPHY, SINCE THE TRIDIMENSIONAL PAINTINGS

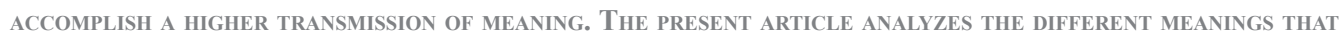
ARISE FROM THIS TRIDIMENSIONAL COMPREHENSION OF THE MOCHICA MYTH THAT IS EMBODIED IN THE VESSELS: “THE WAR OF THE OBJECTS". IN THIS MANNER, WE UNDERSTAND NOT ONLY THE LOGIC OF THE MYTH AND THE SEQUENTIAL CHARACTER IN WHICH IT IS REPRESENTED, BUT ALSO THE SHAPE IN WHICH IS NARRATED -ESSENTIAL AND SECONDARY

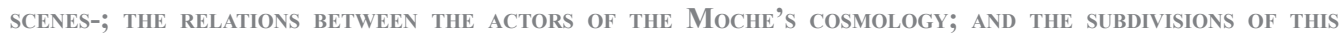
BIPARTITE UNIVERSE - UP WORLD/DOWN WORLD: MALE/FEMALE- APPLIED TO THE TIME ORGANIZATION AND IN ALMOST ANY OTHER PHENOMENON OF THE EXISTING WORLD. FinAlLy THE WAR SCENES IN THE MOCHICA PAINTINGS AS BRIEFLY DISCUSSED.

KeY WORDS: MOCHE - ICONOGRAPHY - MEANING - MYTH.

1 Investigador principal en el Instituto de Estudios Peruanos. Profesor en la Universidad Nacional Mayor de San Marcos. Lima Perú. Correo electrónico: jgolte@iep.org.pe 
$\mathrm{S}$ e ha tratado de entender la iconografía moche durante el siglo XX de una forma especial. Partiendo de las transposiciones de las imágenes de las vasijas a cuadros bidimensionales hechas primero por Wilhelm von den Steinen, un pintor, por encargo de Arthur Baessler (1902-1903) y después utilizadas por Kutscher (1946), el cual les agregó una cantidad considerable de copias propias, con las que trabajaba Annemarie Hocquenghem (1987), y finalmente Donna McClelland que dibujó los cuadros para las publicaciones de Christopher Donnan y de ella (1999), se impuso la utilización de este tipo de imágenes bidimensionales de manera general. Así que los intérpretes trabajaban todos con reproducciones que originalmente estaban pintadas sobre cuerpos tridimensionales, de tal forma que todas las interpretaciones que se hicieron en el siglo XX partían de estas imágenes bidimensionales al estilo europeo. Como hemos argumentado en nuestro libro sobre la iconografía mochica ésta convención etnocentrista impidió en buena medida que se avanzara en la comprensión de la lógica de las pinturas (Golte, 2009). Y es que la pintura tridimensional tiene una amplitud mucho mayor en la creación de significados que la pintura bidimensional.

Se puede ver en una serie de publicaciones que los autores se limitaban a describir las figuras que veían sin lograr comprender el significado de las composiciones moche. Esto se agravaba con las transposiciones que se utilizaban de personas especializadas para ello, pues se sabe que Christopher Donnan daba instrucciones a Donna McClelland para que no copie signos que a él le parecían supérfluos o rellenos, ya que los moche según él tenían un miedo al vacío, aunque el mismo no dibujara ninguno de ellos. En las descripciones que hace en una serie de artículos, y también en su libro con Donna McClelland (1999) esto se nota en una serie de descripciones inexactas (Donnan y McClelland, 1999). Si esto ya era problemático en las pinturas hechas en las botellas de asa estribo y las fuentes conocidas como floreros, alcanzaba niveles muy poco aceptables en las botellas de boca ancha de forma irregular. Por lo general se evitaba escribir sobre ellas, y si se publicaba fotos se las tildaba de "surrealistas"(Ibíd.), en otras palabras se reconocía la incapacidad de comprensión cubriéndose con una palabra que designaba un movimiento artístico y literario surgido en Europa a partir del dadaísmo, en la década de los años de 1920. No deja de sorprender que no se lograba entender la tridimensionalidad de las imágenes, especialmente porque una parte considerable de la cerámica mochica presentaba imágenes en forma de escultura, frecuentemente combinadas con pinturas. En estos casos, más problemático aún, se copiaba las imágenes en la forma bidimensional habituada y se eliminaba simplemente las partes esculturadas de la obra (Kutscher, 1983) (figura 1).

En este artículo nos limitamos a un tema, expuesto en una serie de vasijas de cerámica, que se ha conocido como la "rebelión de los objetos". Este nombre nos parece problemático porque los acontecimientos pintados, si bien se refieren a una guerra de objetos contra los moche, ésta no está dirigida contra sus dueños. Hay que comprender que según la concepción mochica, los objetos no eran súbditos de los moche, sino pertenecían al ámbito de las divinidades del mundo de abajo y como tales estaban luchando contra los moche para entregarlos a la Divinidad Lunar y al dios Búho, que también pertenecían al mundo de abajo, el mundo de la época húmeda. Así que preferimos llamar este mito mochica "la guerra de los objetos".

Hay una versión de este tema en el Museo Etnográfico de Munich. Esta es particularmente interesante porque no sólo ofrece imágenes de la guerra de los objetos, sino también el contexto de ella. Es que la guerra es el inicio de un ciclo en el cual los objetos quitados a los guerreros vencidos por los vencedores son sacrificados al dios de la Vía Láctea que al parecer tiene su templo en una isla. La recolección está a cargo de la diosa Luna y el dios Búho. Estos los podemos ver claramente en la versión de Munich, son los líderes de la confrontación con los moche. La victoria sobre ellos conduce a su traslado al templo del dios de la Vía Láctea. Sin embargo, de ahí regresan a la tierra firme y libran una guerra contra los moche, en la cual parecen ser victoriosos. Sin embargo, y esto es lo particular de la botella de asa estribo de Munich. El dios Sol, con la ayuda de los animales diurnos libra un contrataque contra los objetos y los vence y la diosa Luna es conducida como cautiva al dios Sol. La versión de Munich, en cuanto sepamos 
existe sólo en éste ejemplar, a pesar de que la iconografía moche por lo general repite las escenas en cantidades menores o mayores de vasijas (figuras 2, 3 y 4 ).

Este es el caso de la "guerra de los objetos" sobre la cual existe un número considerable de vasijas que muestran escenas particulares de ella o también la confrontación desde el inicio hasta el fin. De estas conocemos por lo menos cuatro versiones. Una que se encuentra en una colección particular en California, otra que se halla en el Museo Grassi de Leipzig, y finalmente dos más que forman parte de la colección del Museo Larco en Lima. Todas ellas son fácilmente reconstruibles como mito o narración ya que exponen la secuencia de los hechos en un espiral que empieza en la base de la vasija y da vueltas alrededor de su cuerpo hasta culminar finalmente en el polo superior de ésta. Lo interesante, y excepcional, en el caso de la pieza del Museo Grassi, y de las dos versiones del Museo Larco es que deben haber sido elaborados por un mismo pintor (figura 5).

El hecho que un mismo pintor elabore tres versiones sobre la misma temática nos ofrece la posibilidad única de poder entender que un pintor no repetía simplemente el tema elaborado de la misma forma, sino que lo variaba en cada pieza. Esta particularidad abre la posibilidad de observar que para el autor había "escenas esenciales", que aparecen en todas las versiones, y otras que deben haber tenido una importancia secundaria, ya que no aparecen en todas las versiones. Lo dicho, por supuesto también se puede observar en una transposición bidimensional de las imágenes de una vasija (figuras 6 y 7).

Lo extraordinario, sin embargo, que recién se comprende cuando se dispone de varias versiones del mismo autor y se las puede observar en su exposición tridimensional, es que a pesar de la variación en la cantidad de vueltas del espiral, de acuerdo al hecho que una versión puede ser más larga que las otras por ofrecer más detalles, es que el autor no sólo expone el mito en una narración continuada sobre la vasija, sino que al mismo tiempo respeta un orden que informa sobre la relación entre los actores en la cosmología de los moche. Es que ella partía de la idea de una cantidad de actores divinos entrelazados entre ellos, probablemente por parentesco. Esta cosmología la encontramos en las pinturas de todas las culturas centro andinas del período del Intermedio Temprano, pero parece tener una historia más larga desde los principios de la exposición visual en la cerámica centro andina (alrededor de 2500 a 3000 a.C.) que se prolonga hasta la época incaica, y con algunas rupturas causadas por la extirpación de idolatrías en la colonia hasta el día de hoy. En otras palabras también el cristianismo andino es caracterizado por múltiples divinidades, aunque todos se llamen Cristo, o tengan los nombres de vírgenes y santos. Y en las ideas de los pobladores de origen precolombino, todos ellos están emparentados. En la época precolombina el parentesco se extiende también a tipos diversos de humanos, de animales, y especialmente de plantas alimenticias. En la época precolombina se muestra en las pinturas identificadores de grupos de parentesco especialmente en el tocado de las personas. La descendencia de las divinidades primordiales es patrilinear, mientras que en el cinturón la descendencia de los seres primordiales es matrilinearidad (Golte, 2003) (figura 8).

Ahora, lo importante en ello es que la cosmovisión no sólo muestra actores, sino subdivisiones generalizables en un universo bipartito, el mundo de arriba y, separado por el límite de la superficie terrestre, el mundo de abajo. El mundo de arriba es primordialmente masculino, el mundo de abajo femenino. Esta subdivisión se vuelve más compleja, ya que cada parte en si nuevamente se puede subdividir en mitades complementarias. Esta visión del mundo es aplicado a la organización del tiempo, básicamente entre época seca y época húmeda. Pero sirve también para ordenar el espacio y prácticamente todo fenómeno en el mundo existente.

Para que se vea la complejidad de la organización quizás baste mencionar a manera de ejemplo que las flautas de pan las hay con tonos masculinos, y otras con tonos femeninos, tienen que ser tocados en pareja para producir una melodía completa. Este hecho se puede observar hasta hoy en la sierra sur peruana y el altiplano boliviano. En otras regiones los géneros se adscribe a instrumentos de música específicos (Baumann, 1996) (figuras 9, 10, 11 y 12). 
Los autores de las vasijas mencionadas tenían este orden en la cabeza y al pintar una narración continuada sobre una vasija, que a su vez tiene una superficie subdividida en oposiciones complementarias, especialmente las caras en las botellas de asa estribo, pero la subdivisión también puede ubicarse en la parte superior de la vasija, opuesta a la parte inferior. Así que el autor por un lado tiene que respetar la secuencia de la narración, pero igualmente tiene que respetar como logra que los actores estén ubicados en la superficie de la botella que les corresponde. Lo dicho se puede observar perfectamente en las vasijas mencionadas.

La botella de la colección privada en California es bastante semejante a las anteriores, pero tiene una particularidad, que muestra muy bien la relación entre el dios de la Vía Láctea y la diosa Luna. Los dos deben, de acuerdo a su indumentaria estar relacionados estrechamente. La diosa Luna podría ser la hija del de la Vía Láctea. Esto se ve en la vasija de California en el hecho en que la escena final los dos actores brindan juntos con vasos el líquido que han acarreado en las botellas guardadas en las embarcaciones. Se ve en sus atuendos que tienen tanta semejanza que se los puede confundir, lo que efectivamente ha pasado a una serie de autores. Lo interesante para la exposición en las tres botellas anteriormente discutidas es que la diosa Luna, que aparece varias veces en el transcurso de la narración, siempre se ubica en la cara ocupada en la cima por la Divinidad de la Vía Láctea. Es decir, que el autor respetaba el parentesco ubicándola en la misma cara dominada por ésta divinidad (figura 13).

Si bien este artículo está centrado sobre el desenvolvimiento de la "guerra de los objetos" hay que mencionar que la narración resulta más comprensible, si se observa las escenas de guerra en las pinturas mochica. Estas pueden ser multipersonales, pero el enfrentamiento siempre es caracterizado por dos actores opuestos. Cuando uno de los guerreros está vencido, su adversario lo desviste y sólo queda una soga alrededor de su cuello. Esta soga es indicador de que el vencido va a ser sacrificado a una divinidad. La vestimenta y los instrumentos bélicos del adversario también son recolectados y forman parte de otros sacrificios que se hace a las divinidades, como ya lo mencionamos al principio. Los cautivos humanos pueden tener importancia por su sangre en unos casos en otros casos se sacrifica el semen de los hombres especialmente al mundo de femenino de abajo (figura 14). 

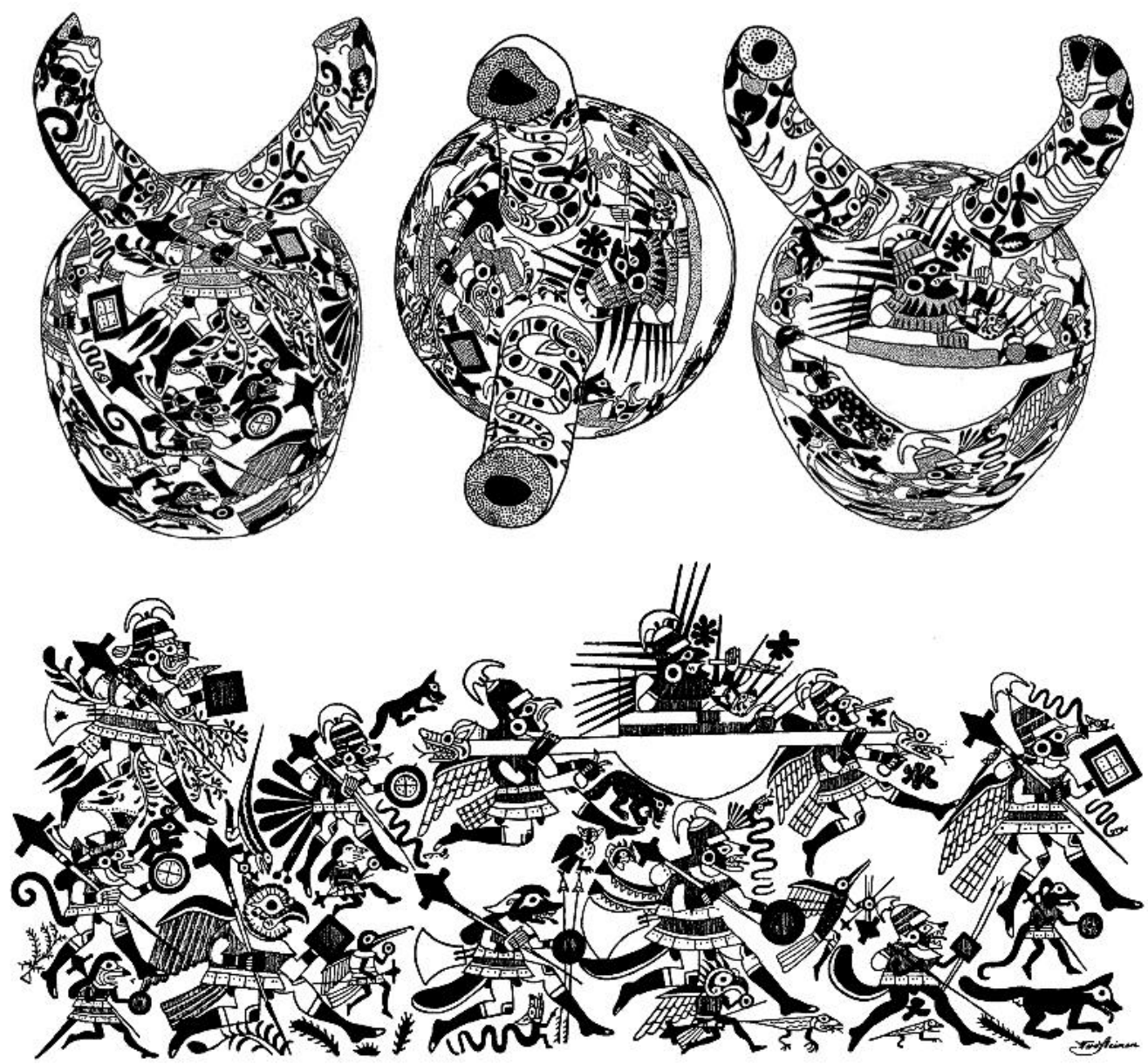

Figura 1. Una transposición de Wilhelm von den Steinen (Kutscher, 1954) e imágenes de las vasiJas en la CUAL SE OBSERVA QUE EL ORDEN BIDIMENSIONAL NO PERMITE COMPRENDER LA SUBDIVISIÓN EN UN FRENTE DE LA

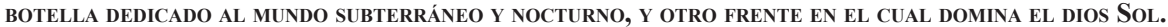




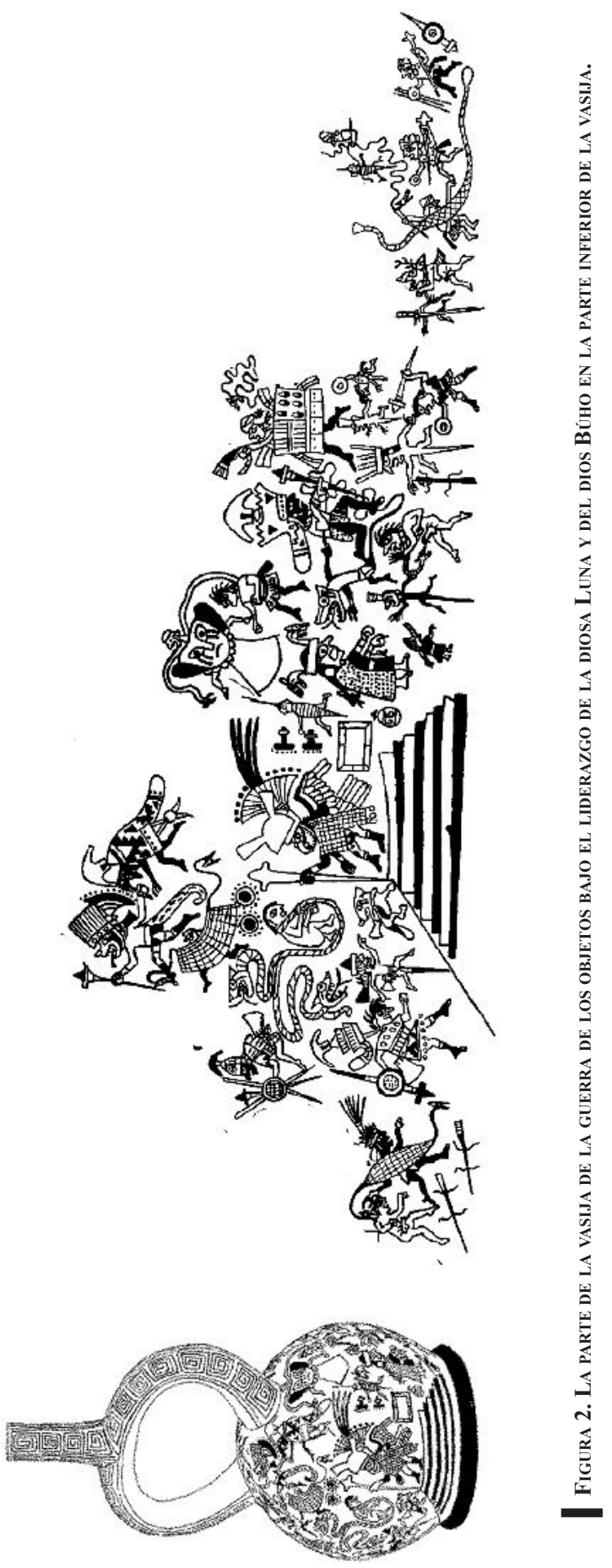



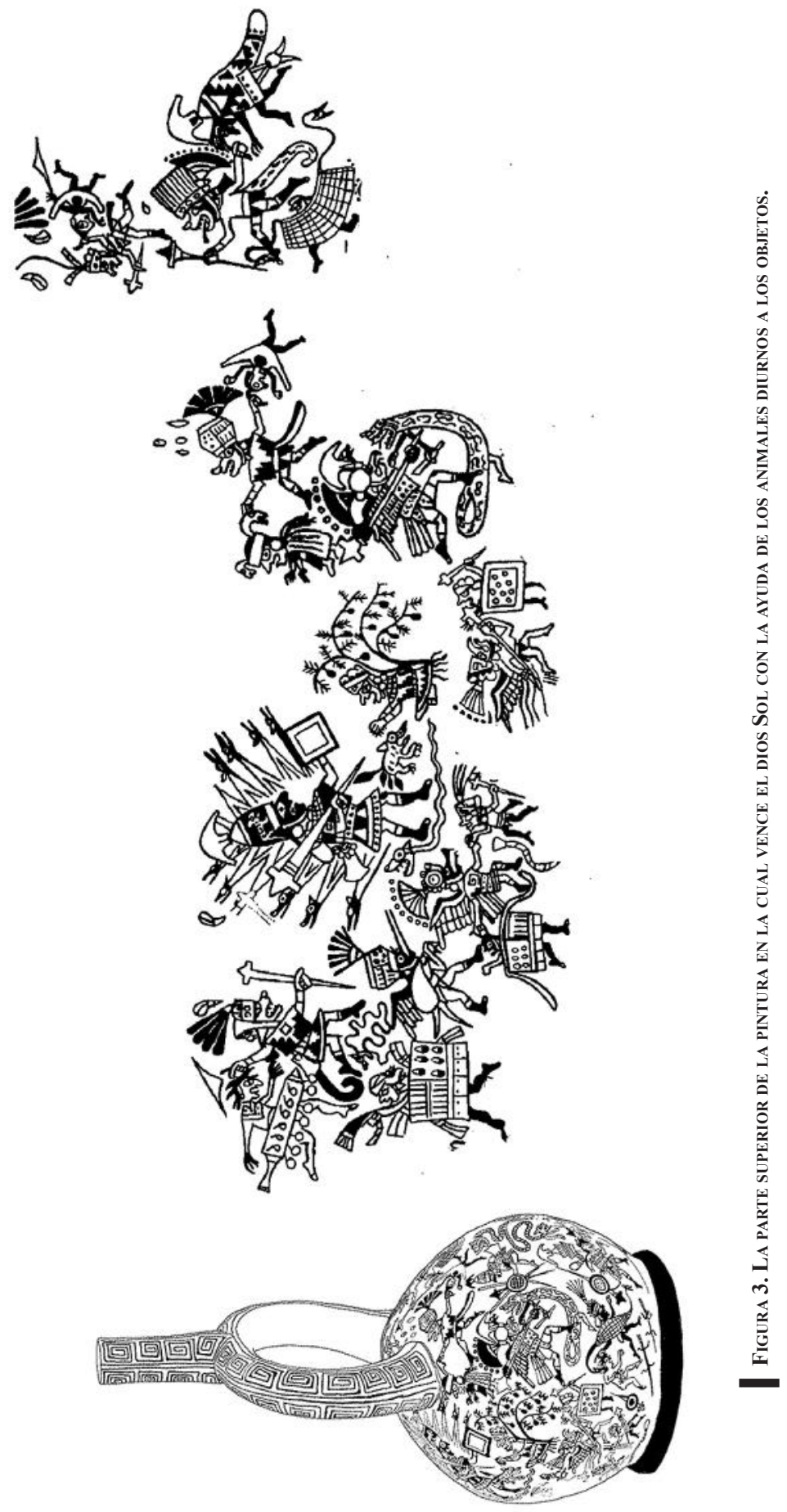


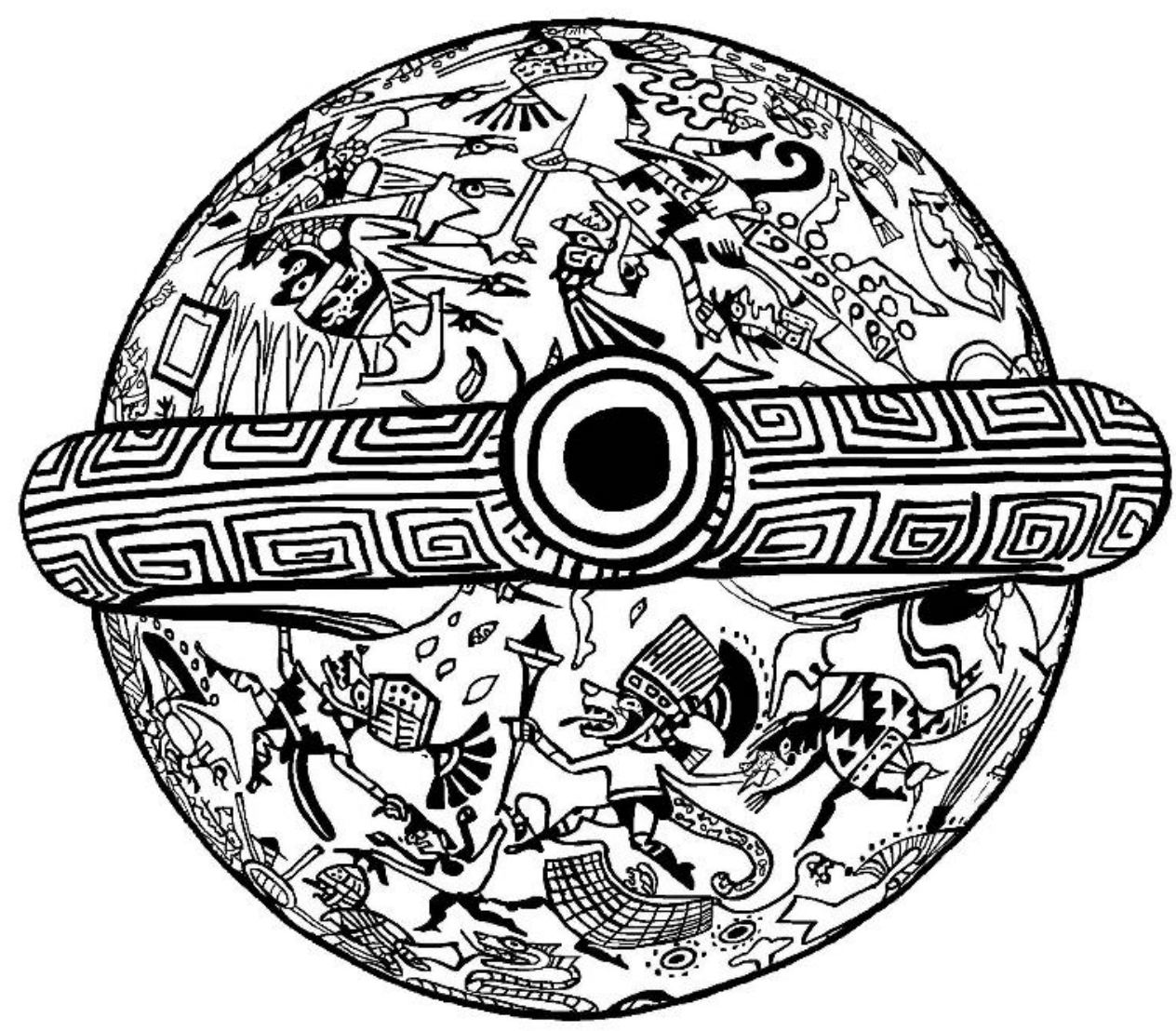

Figura 4. Una Vista de arriba de la botella en la cual Se ObServa Que es dedicada a la Victoria del dios Sol. 

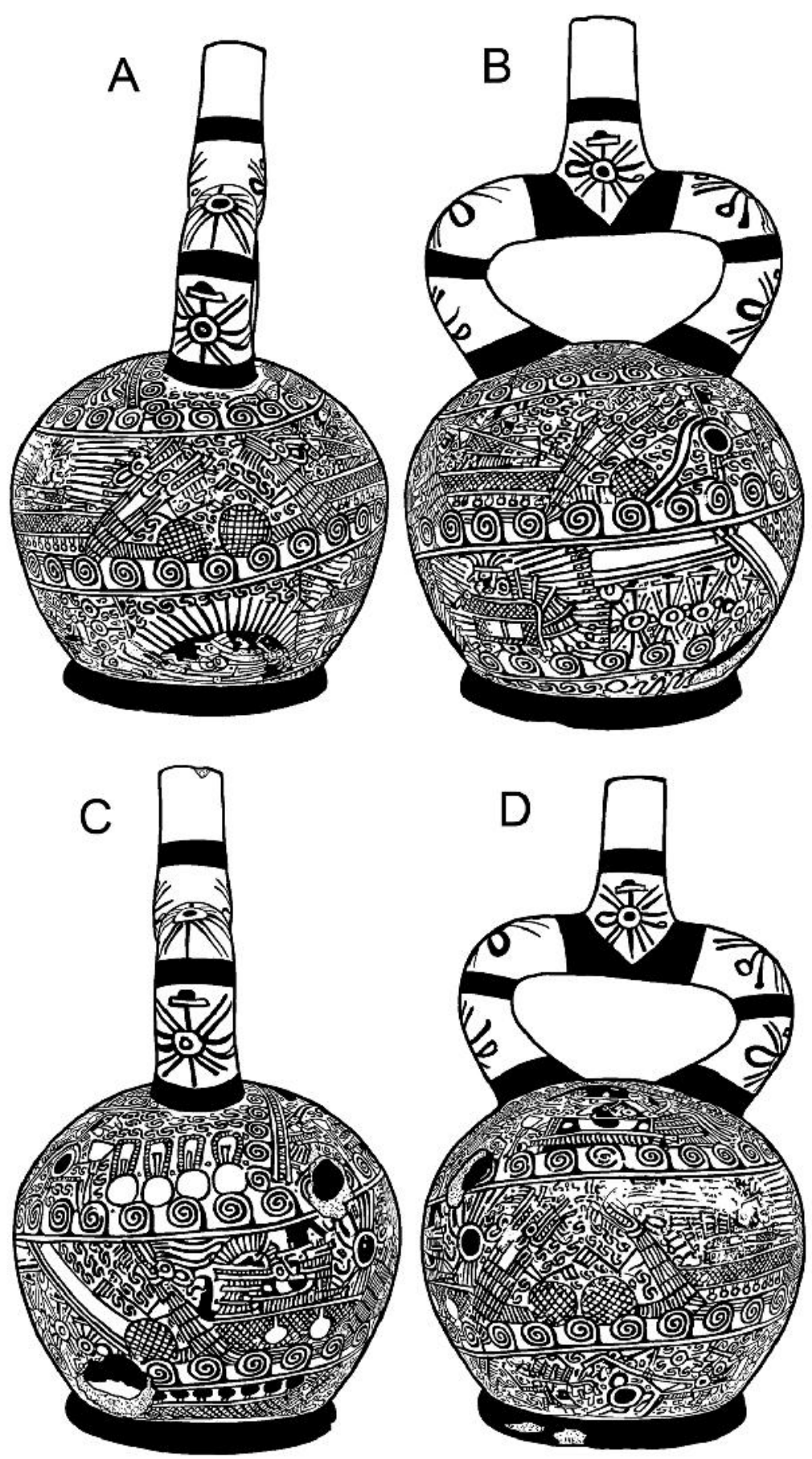

Figura 5. La versión de la vasija del muSeo Grassi en Leipzig (SAm 6897). 

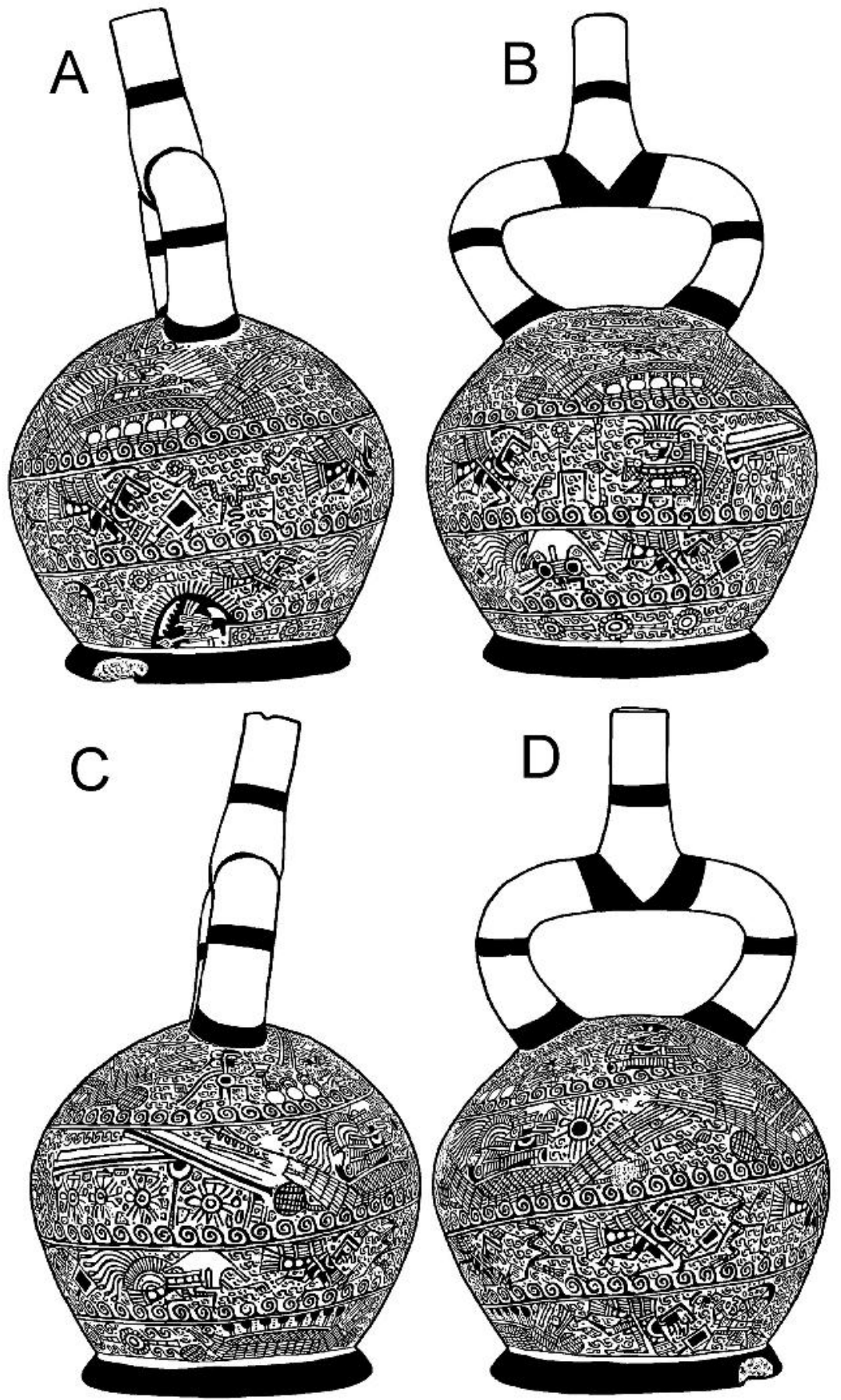

Figura 6. La Vasija del museo Larco con la Versión más eXtensa del mito (ML 013610). 


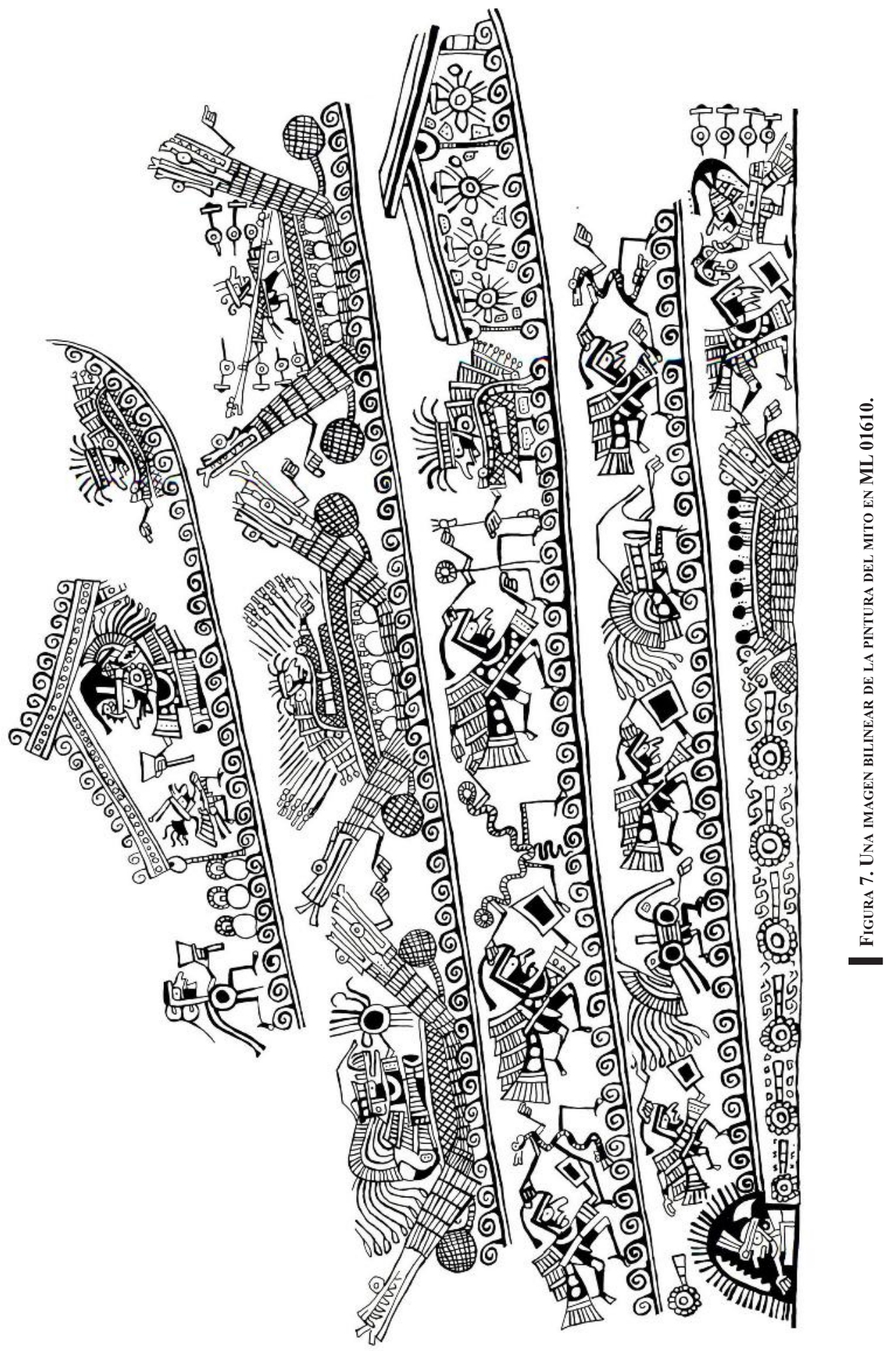




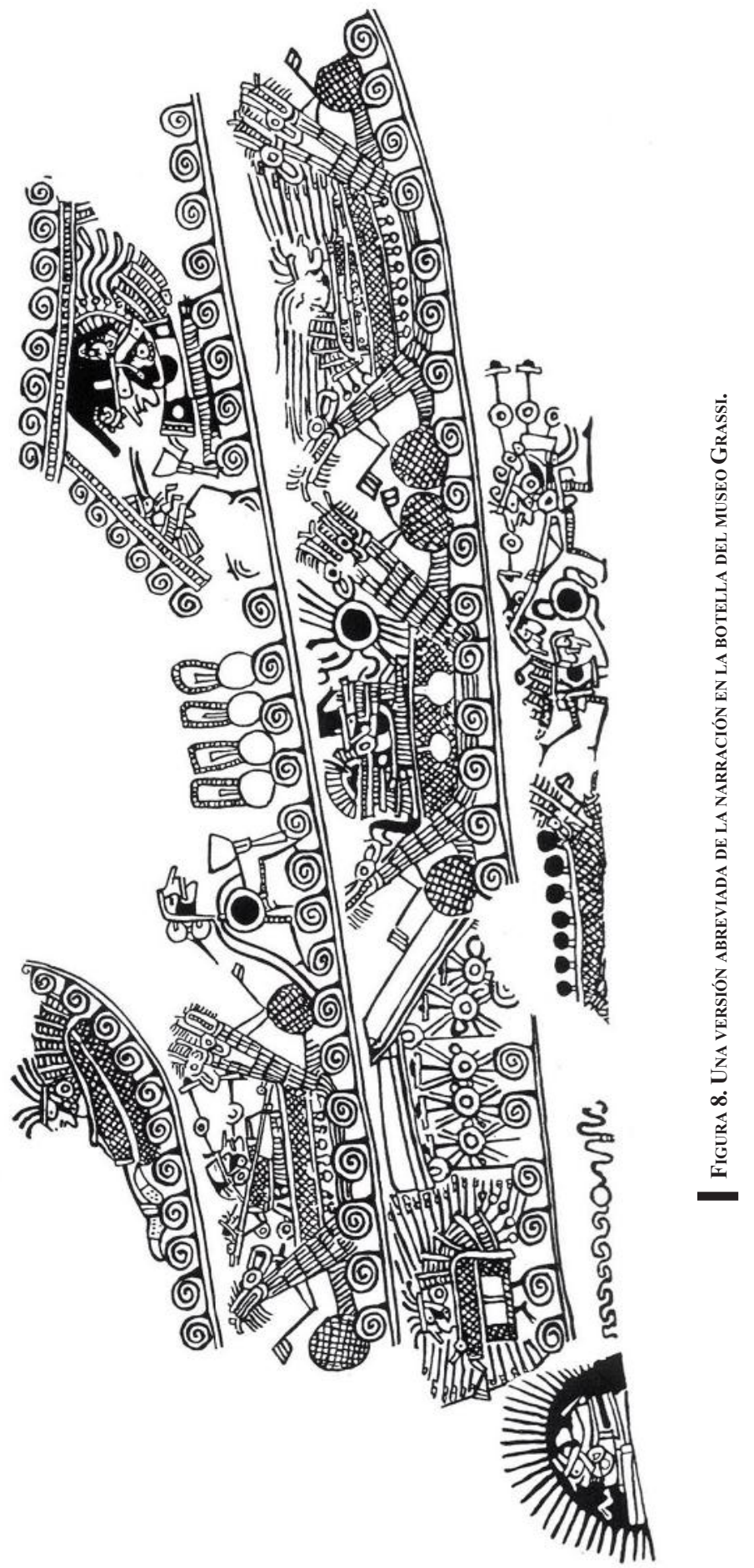



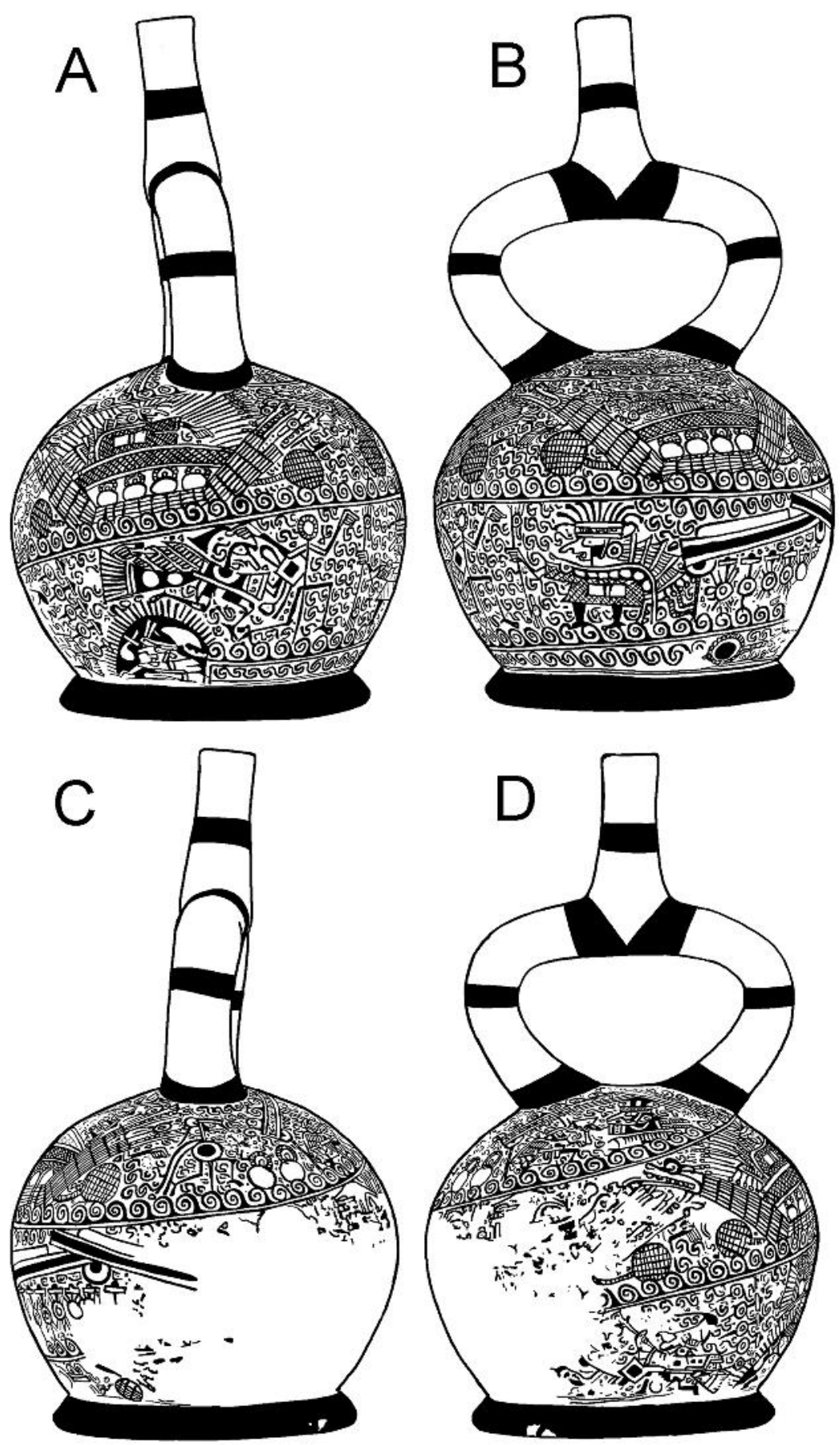

Figura 9. La versión algo dañada del museo Larco (ML013664). 


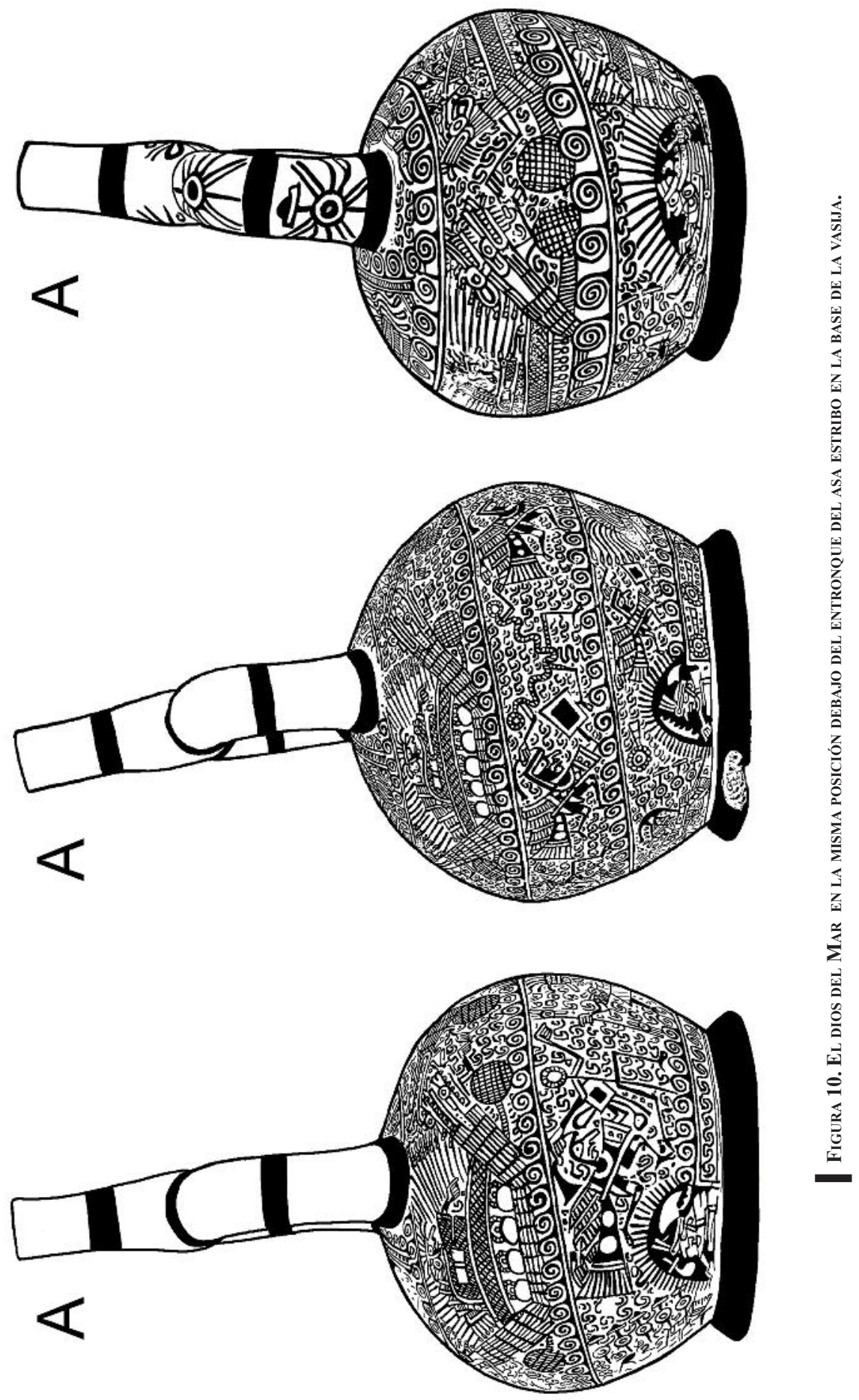



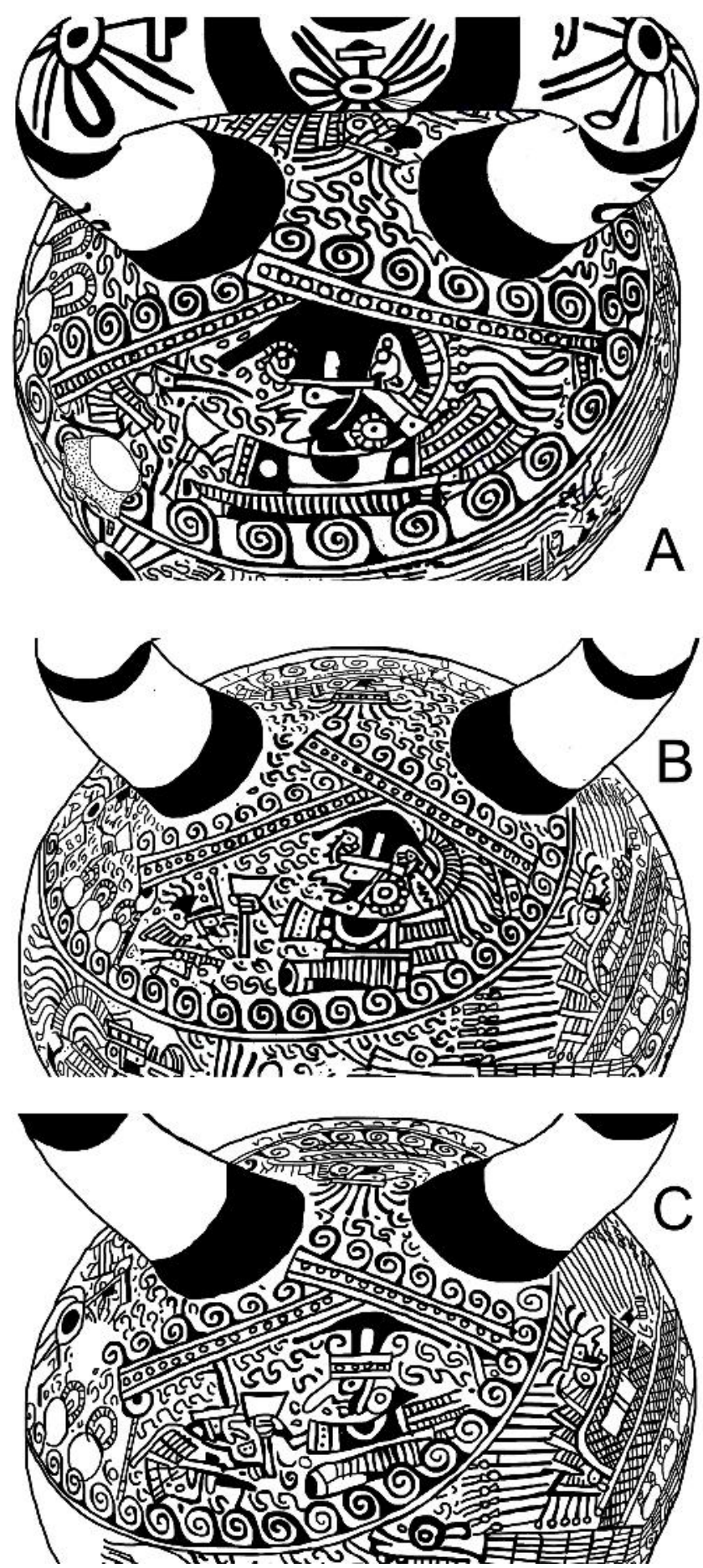

Figura 11. El dios BúHo EN LA MISMA POSICIÓN EN LA PARTE SUPERIOR ENTRE LOS ENTRONQUES DEL ASA ESTRIBO DE LAS TRES VASIJAS. 

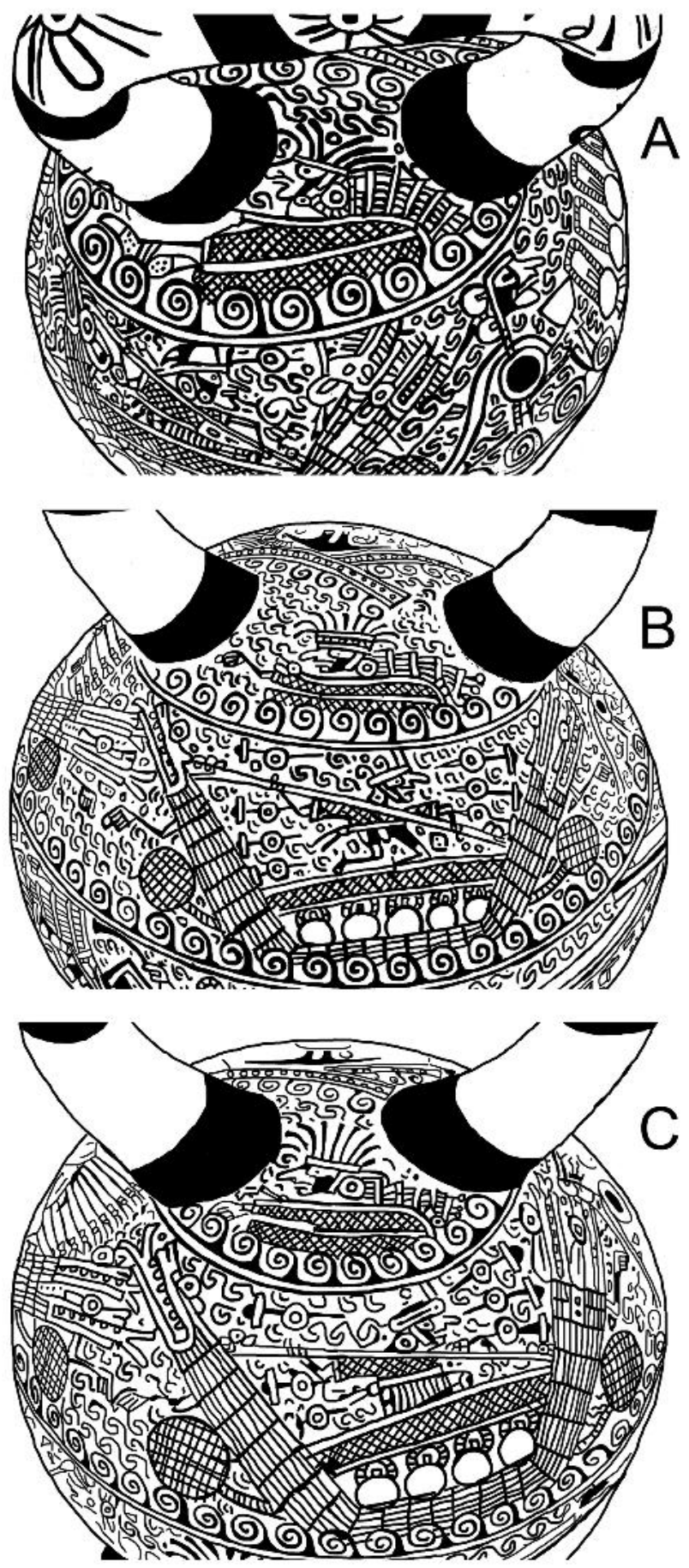

Figura 12. El dios de la Vía Láctea en la misma posición en las tres VaSiJas en el lado OPUESTO AL BÚHO ENTRE LOS ENTRONQUES DEL ASA ESTRIBO 


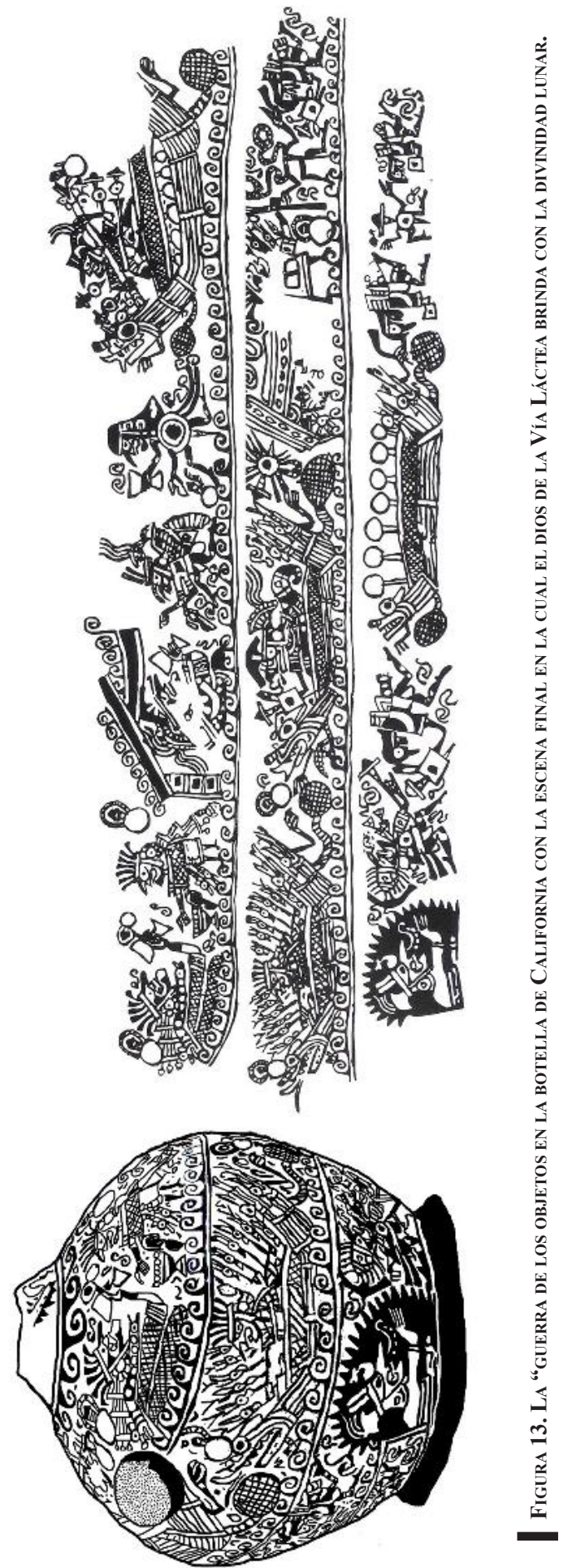




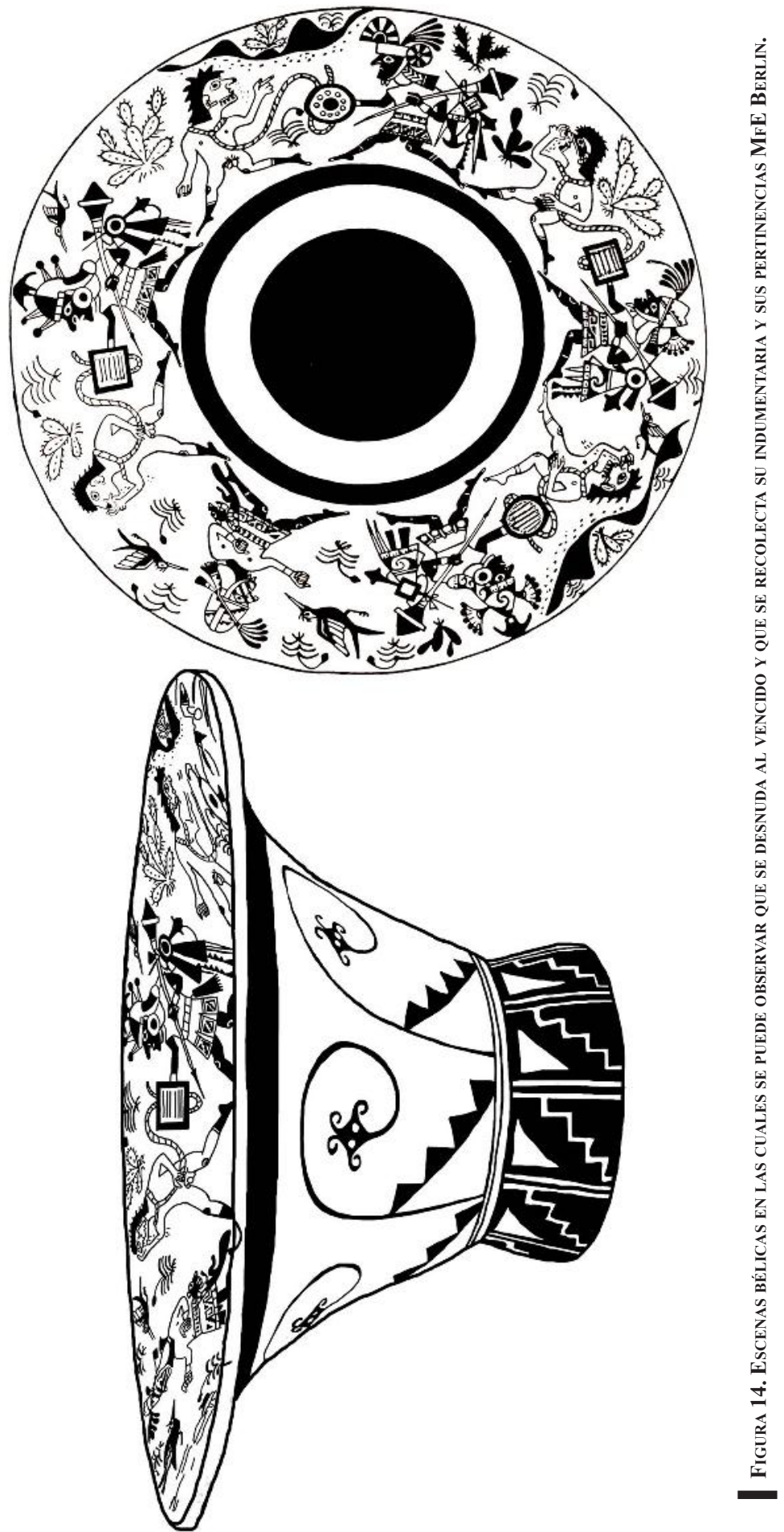




\section{Bibliografía}

Baessler, Arthur, 1902-03, Altperuanische Kunst. Beiträge zur Archäologie des Inka-Reiches nach seinen Sammlungen. Berlin: K. Hiersemann und A. Ascher.

Baumann, Max Peter, 1996, “Andean music, symbolic dualism and cosmology”, en: Max Peter Baumann (ed.) Cosmología y música en los Andes, Frankfurt/Madrid: Vervuert/Iberoamericana, pp: 15-66.

Bawden, Garth, 1996, The Moche. Cambridge/Mass, Oxford: Blackwell.

Berezkin, Yuri E. 1983, Mochika. Leningrado: Academia de Ciencias de la URSS.

1978, Khronologiya srednego i pozdnego etapov kul 'turë Mochika (Perú). Sovietskaya Arkheologiya 2, pp: 78-95.

Bock, Edward K. de, 1988, Moche: Gods, Warriors, Priests. Leiden: Rijksmuseum voor Volkenkunde.

1988, Moche: Gods, Warriors and Priests, Leiden: Rijksmuseum voor Volkenkunde.

Bolaños, César, 1988, Las Antaras Nazca. Lima.

Bourget, Steve, 1994, El mar y la muerte en la iconografía Moche, en: Santiago Uceda y Elías Mujica B. (eds.), Moche: propuestas y perspectivas. Lima: IFEA.

1990, Des tubercules pour la mort: analyses préliminaires des relation entre l'ordre naturel et l'ordre culturel dans l'iconographie Mochica, Bulletin de l'Institut Français d'Etudes Andines 19(1), pp: 45-85.

1989, Structures magico-réligieuses et idéologies de l'iconographie Mochica IV. [Memoria de maestría, Montreal, Universidad de Montreal, Departamento de Antropología].

Campana Delgado, Cristóbal, 1995, La cultura Mochica. Lima: CONYTEC.

Castillo Butters, Luis Jaime, 1989, Personajes míticos, escenas y narraciones en la iconografia mochica. Lima: Fondo Editorial, Pontificia Universidad del Perú.

Cordy-Collins, Alma, 1977, The Moon is a Boat! A Study in Iconographic Methodology, en: Alma Cordy-Collins y J. Stern (Eds.), Pre-Columbian Art History. Selected Readings, Palo Alto: Peek Publications, pp. 421-434.

Donnan, Christopher and Donna McClelland, 1999, Moche Fineline Painting: its Evolution and its Artists. Los Angeles: UCLA Fowler Museum of Cultural History.

Donnan, Christopher B., 1975, The Thematic Approach to Moche Iconography. Journal of American Lore 1(2), pp: 147-162.

Golte, Jürgen y Anne Marie Hocquenghem, 1984, Seres míticos y mujeres: interpretación de una escena Moche, Table ronde sur les collections précolombiennes dans les musées européens, Viena: Centro Europeo de Coordinación de Investigación y Documentación en Ciencias Sociales, pp. 91-112.

Golte, Jürgen y Rodolfo Sánchez, 2004, Sawasiray-Pitusiray, la antiguedad del concepto y santuario en los Andes. Investigaciones Sociales, Revista del Instituto de Investigaciones Histórico-Sociales UNMSM Año VIII (13), pp. $15-29$.

Golte, Jürgen, 2009, Moche. Cosmología y Sociedad. Una interpretación iconográfica.

2006, Un universo oculto. Baessler-Archiv 52, pp.125-174.

2005, La construcción de la naturaleza en el mundo prehispánico andino, su continuación en el mundo colonial y en la época moderna. Revista de Antropología, Cuarta Época Año 3 (No. 3), pp.13-62.

2004, Divinidades femeninas moche, en: Dorothea Ortmann (ed.), Las religiones en el Perú de hoy, Lima: UNMSMCONCYTEC, pp. 165-220.

2003, La iconografía nazca. Arqueológicas 26, pp. 178-218.

1998, "Las formas de generación de sentido en los cuerpos de íconos moche y nasca", en: Universidad de Lima (ed.), I Encuentro Internacional de Peruanistas. Estado de los estudios histórico-sociales sobre el Perú a fines del siglo XX, Lima: Universidad de Lima, Unesco, Fondo de Cultura Económica. tomo II), pp. 55-106.

1996, "Una paradoja en la investigación etnohistórica andina", en: Max Peter Baumann (ed.), Cosmología y música en los Andes, Frankfurt/Madrid: Vervuert/Iberoamericana, pp. 519-531.

1994, Methode und Wahrnehmung: Probleme beim Verständnis der Moche-Vasenmalerei, en: Axel Schönberger y Klaus Zimmermann (Eds.), De orbis Hispani linguis litteris historia moribus. Festschrift für Dietrich Briesemeister zum 60. Geburtstag, Frankfurt/Main., 2. pp. 1139-1151.

1994, Íconos y narraciones. La reconstrucción de una secuencia de imágenes moche. Lima: Instituto de Estudios Peruanos.

Hocquenghem, Anne Marie, 1987, Iconografia Mochica. Lima: Fondo Editorial, Pontificia Univesidad Católica del Perú.

Horkheimer, Hans, 1961, La cultura mochica. Lima: Compañía de Seguros y Reaseguros Peruano-Suiza. (Serie Las grandes civilizaciones del Antiguo Perú 1). Moche, Lima: Banco de Crédito del Perú, pp. 17-51.

Klein, Otto, 1967, La cerámica mochica: caracteres estilísticos y conceptos. Scientia 131.

Kutscher, Gerdt V., 1983, Norperuanische Gefäßmalereien des Moche-Stils. Bonn. (Materialien zur Allgemeinen und Vergleichenden Archäologie 18). 
1954, Nordperuanische Keramik. Figürlich verzierte Gefäße der Früh-Chimu. Cerámica del Perú septentrional. Figuras ornamentales en vasijas de los Chimúes antiguos. Berlín: Gebr. Mann. (Monumenta Americana 1).

1950, Sakrale Wettläufe bei den Frühen Chimú (Nordperu). Beiträge zur Gesellungs- und Völkerwissenschaft, pp. 209226.

1950, Cimú. Eine altindianische Hochkultur. Berlín: Gebr. Mann.

1946, Die figürlichen Vasenmalereien der frühen Chimú (Alt-Peru). [tesis inédita, Berlín, Friedrich Wilhelms Universität, Larco Hoyle, Rafael, 2001. Los mochicas. Lima, Fundación Telefónica.

1945, Los Mochicas (Pre-Chimu de Uhle y Early Chimu de Kroeber). Buenos Aires: Sociedad Geográfica Americana.

Lavalle, José Antonio de (Ed.) 1985, Culturas Precolombinas: Moche. Lima: Banco de Crédito del Perú, (colección Arte y Tesoros del Perú).

Lieske, Bärbel, 1992, Mythische Erzählungen in den Gefäßmalereien der altperuanischen Moche-Kultur. Versuch einer ikonographischen Rekonstruktion. Bonn: Holos Verlag.

Makowski, Krzysztof, 1994, La figura del 'oficiante’ en la iconografía mochica: ¿shamán o sacerdote? en: Luis Millones, Moisés Lemlij y Dana Cáceres (eds.), En el nombre del Señor: Shamanes, demonios y curanderos del norte del Perú. Lima: Biblioteca Peruana de Psicoanálisis, (colección biblioteca Peruana de Psicoanálisis 19).

McClelland, Donna D., 1990, A Maritime Passage from Moche to Chimu. en: Michael E. Moseley y Alma Cordy-Collins (Eds.), The Northern Dynasties: Kingship and Statecraft in Chimor. Washington, D.C.: Dumbarton Oaks Research Library and Collection.

Mejía Xesspe, Toribio, 1952, Mitología del norte andino peruano. América Indígena 12(3), pp. 235-251.

Quilter, Jeffrey, 1990, The Moche Revolt of the Objects. Latin American Antiquity 1(1), pp. 42-65.

Vergara Montero, Enrique y Manuel Sánchez Vera, 1996. Mitografia mochica. Trujillo: Universidad Nacional de Trujillo. 